\title{
Article \\ Correlation between Underwater Noise and Sea Level at Ieodo Ocean Research Station
}

\author{
Seong Hyeon Kim $\mathbb{B}^{0}$, Bok Kyoung Choi and Byoung-Nam Kim*
}

check for

updates

Citation: Kim, S.H.; Choi, B.K.; Kim, B.-N. Correlation between Underwater Noise and Sea Level at Ieodo Ocean Research Station. J. Mar. Sci. Eng. 2021, 9, 1. https://dx.doi.org/10.3390/ jmse9010001

Received: 19 November 2020 Accepted: 19 December 2020 Published: 22 December 2020

Publisher's Note: MDPI stays neutral with regard to jurisdictional claims in published maps and institutional affiliations.

Copyright: (c) 2020 by the authors. Licensee MDPI, Basel, Switzerland. This article is an open access article distributed under the terms and conditions of the Creative Commons Attribution (CC BY) license (https: / / creativecommons.org/ licenses/by/4.0/).
Maritime Security and Safety Research Center, Korea Institute of Ocean Science and Technology, Busan 4911, Korea; kenta81@kiost.ac.kr (S.H.K.); bkchoi@kiost.ac.kr (B.K.C.)

* Correspondence: bnkim@kiost.ac.kr; Tel.: +82-51-664-3661

\begin{abstract}
To investigate the correlation between underwater noise and sea level, data collected at Ieodo Ocean Research Station (from 15 May to 27 August 2013) were analyzed. Temporal variations in the overall level of underwater noise were similar to those in sea level. The average underwater noise levels at frequencies below $50 \mathrm{~Hz}$ were 99.0-106.6 dB during spring tides and 78.4-90.2 dB during neap tides, with a difference of 12.6-20.6 dB. When low-pass filtering at six hours was applied to the absolute value of sea level, a high correlation coefficient of 0.7 for its association with underwater noise was obtained. This strong correlation could indicate flow noise caused by currents. Underwater noise levels around the frequency of $16 \mathrm{~Hz}$ were relatively strongly correlated with sea level (correlation coefficient of 0.71). Wavelet analysis of the overall level of underwater noise showed strong periodicity at $0.25,0.50,1.0,16.0$, and 30.0 days, as well as characteristics of a tidal constituent. In wavelet coherence analysis, the overall level at a period of 0.25 days exhibited a phase difference of -90 degrees relative to sea level. This finding indicates that the noise level peaks at $1.5 \mathrm{~h}$ before the high tide or low tide, which was confirmed in the correlation analysis of noise level and sea height with various time lags. This study shows that the overall level of underwater noise from ebb currents is higher than that from flood currents due to differences in current velocity.
\end{abstract}

Keywords: underwater noise; flow noise; wavelet analysis; sea level; Ieodo Ocean Research Station (IORS)

\section{Introduction}

The northern area of the East China Sea has complicated flow patterns due to the coexistence of a variety of currents (Kuroshio, Jeju Warm Current, and others) and tides [1] There are also rotating tides that move in a clockwise direction near Jeju Island, South Korea. This area has a typical semidiurnal tidal cycle, in which the tide stage and direction change with time in the tidal cycle, and the strength of the tide changes between spring and neap tides [2]. Ieodo Ocean Research Station (IORS; $125^{\circ} 10^{\prime} 56.81^{\prime \prime}$ E, $32^{\circ} 07^{\prime} 22.63^{\prime \prime} \mathrm{N}$ ) was constructed around underwater rocks at $149 \mathrm{~km}$ southwest of Mara Island off Jeju Island (Figure 1) in 2003 [3]. Characteristics of the surrounding marine environment including water temperature, current, wave height, and underwater ambient noise are observed using a variety of sensors installed at IORS.

Underwater ambient noise in the ocean exhibits very different patterns in response to shipping, wind, marine life, breaking waves, rainfall, and water flow [4-18]. Generally, underwater ambient noise caused by water flow in the ocean is generated at frequencies below $100 \mathrm{~Hz}[6,9,10,12,14-16]$. Such underwater noise is frequently called flow noise or pseudosound, a type of non-acoustic noise $[6,7,11]$, as water flow can cause pressure fluctuations near the surface of the moored underwater hydrophone in the ocean. However, flow noise can be an important factor when investigating the characteristics of tides [16-18].

Previous studies on flow noise in the ocean caused by tides have mostly investigated the relationship between sea level and flow velocity [16-18]. These studies have shown that significant flow noise at $4.5 \mathrm{~Hz}$ can be observed due to semi-diurnal tides, and flow 
noise can occur at frequencies of up to $500 \mathrm{~Hz}$ as tidal current velocity increases [16,17]. Willis et al. [18] reported that the underwater noise level related to tides can be higher during ebb tides than flood tides at Ramsey Island in the United Kingdom. However, previous studies did not specifically analyze the correlation strength and periodicity of the relationship between flow noise and tidal data. Therefore, in this study, we investigated the correlations and periodicity of underwater noise, sea level, and current velocity observed at IORS.

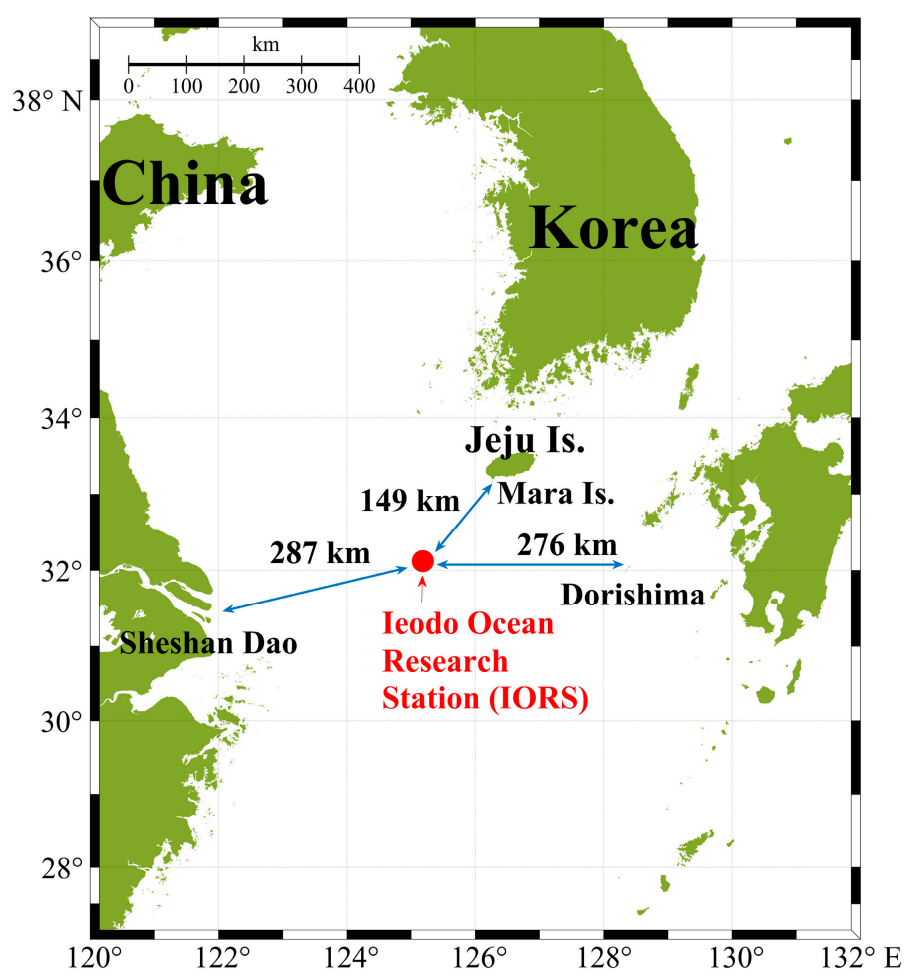

Figure 1. Location of the Ieodo Ocean Research Station (IORS). IORS is situated on Ieodo Rock, an underwater rock located approximately $149 \mathrm{~km}$ southwest of Mara Island.

\section{Data and Methods}

\subsection{Underwater Noise}

Figure 2 shows a schematic diagram of the experimental setup used for acoustic measurement of underwater noise. The water depth at IORS was $50 \mathrm{~m}$. A self-recording hydrophone (SM2M, Wildlife Acoustics Inc., Maynard, MA, USA) consisting of a hydrophone sensor (HTI-96-MIN, High Tech Inc., USA), a 16-bit analog-to-digital converter, an amplification circuit, the main control unit, an SDXC (Secure Digital Extended Capacity) memory card, and a dry battery was deployed at a water depth of between 18 and $20 \mathrm{~m}$. To minimize fluctuations in hydrophone position due to wave action and strong currents, the self-recording hydrophone was attached to a wire cable with a diameter of $5 \mathrm{~mm}$, which was held vertical using a weight of $600 \mathrm{~kg}$ near the bottom to minimize the strumming noise. The hydrophone sensor has a nearly omni-directional receiving sensitivity of $-165 \mathrm{~dB}$ re $1 \mathrm{~V} / \mu \mathrm{Pa}$ within $\pm 3 \mathrm{~dB}$ in the frequency range of $2 \mathrm{~Hz}-30 \mathrm{kHz}$. Underwater noise was measured for $1 \mathrm{~min}$ at 30-min intervals over $24 \mathrm{~h}$ from 15 May to 27 August 2013. Data were recorded on an SDXC memory card at a sampling rate of 44,100 $\mathrm{Hz}$. 


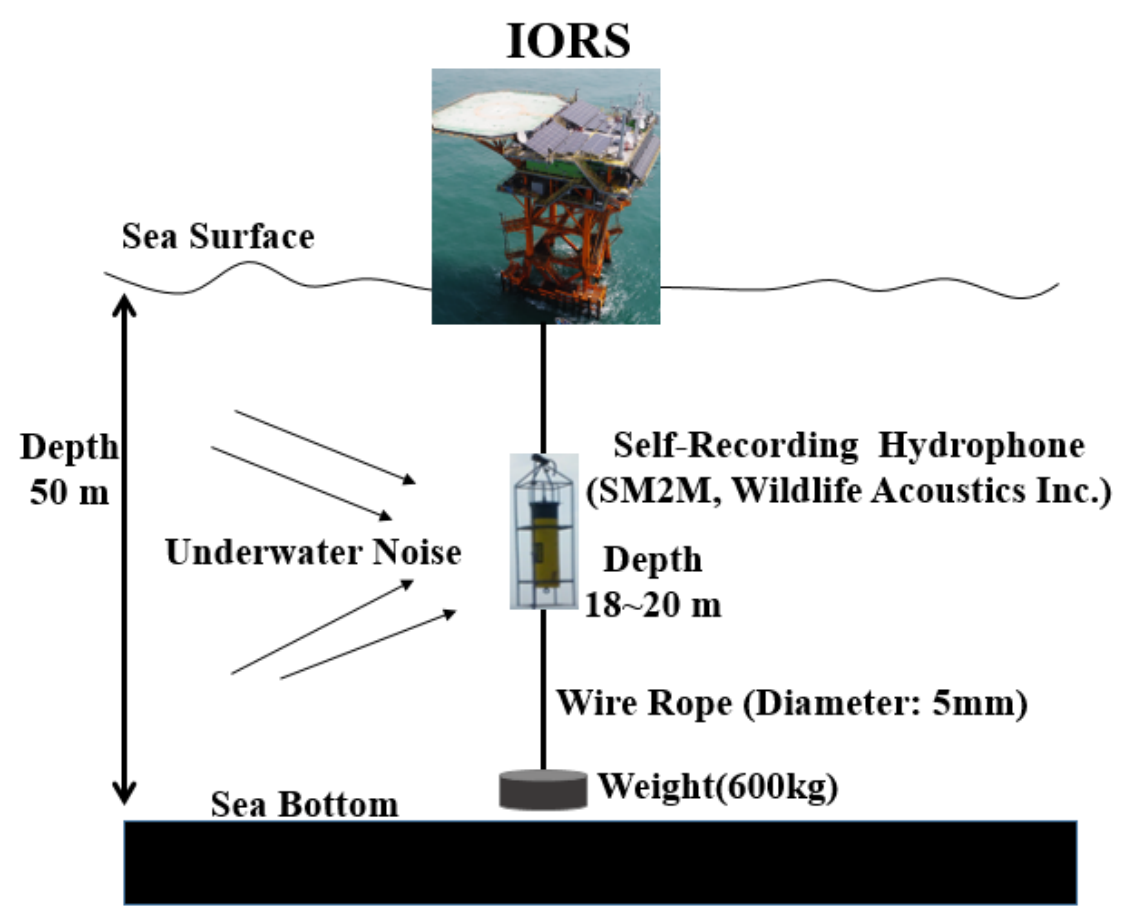

Figure 2. Schematic diagram of the experimental setup used for acoustic measurement of underwater noise.

A 1/3-octave analysis was performed to obtain the mean noise spectra of underwater noise over the frequency range of $10 \mathrm{~Hz}-12.5 \mathrm{kHz}$ [19]. The sampling rate is $44,100 \mathrm{~Hz}$, but maximum useable frequency is generally $1 / 3$ times of the sampling frequency. Therefore, the maximum frequency at $1 / 3$-octave analysis was $12.5 \mathrm{kHz}$. The duration of each underwater noise used for analysis was $1 \mathrm{~s}$. The overall intensity of $1 / 3$-octave levels was used to analyze the correlation between underwater noise and sea level, and is given by:

$$
I L=10 \log \left(\sum_{i} 10^{\frac{I L_{i}}{10}}\right)
$$

where $I L_{i}$ is the intensity level of the $i$ th $1 / 3$-octave frequency.

\subsection{Sea Level and Current Velocity}

Sea level was measured every $10 \mathrm{~min}$ from 15 May to 27 August 2013 using a wave radar device (RangeFinder, Miros, Norway) that was installed on a steel frame at IORS and located at a height of $24 \mathrm{~m}$ above the sea surface. These data were rearranged in 30-min intervals for comparison with the overall underwater noise level measurements. The mean sea level (MSL), which has been measured since 2004 by the Korea Hydrographic and Oceanographic Administration, was $135 \mathrm{~cm}$ [20]. Therefore, sea levels in this study were determined by subtracting the MSL from our measured sea levels.

The current velocity must be measured for correlation analysis of the overall level of underwater noise and sea level. A recording Doppler current meter (RDCP 600, Aanderaa) was installed on the sea bottom a few tens of meters away from IORS. However, as this instrument was frequently lost due to fishing operations around IORS, no current velocity data were collected in 2013. Therefore, we used current velocity data obtained every $30 \mathrm{~min}$ from 17 October 2009 to 20 February 2010.

\subsection{Correlation and Continous Wavelet Transform Analyses}

Sea level is a vector value that has a directional component. However, the underwater noise level is a scalar value that is not directional. Therefore, absolute values of sea level were taken for comparison with underwater noise data. Low-pass filtering at $6 \mathrm{~h}$ was 
applied to overall levels of underwater noise for long-period analysis of the correlation between noise level and sea level. The continuous wavelet analysis was performed to analyze the coherence between the overall level of underwater noise and sea level. For wavelet calculation, MATLAB code was used, which was made by A. Grinsted. The type of wavelet was 'Morlet' [21]. This type provides a good balance between time and frequency localization.

\section{Results}

Figure 3 shows the sea levels and overall levels of underwater noise from 15 May to 27 August 2013. During the measurement period, seven spring tides and neap tides occurred, as shown in Figure 3a. The peak of each spring tide is marked with a yellow dot. The sea level curve repeated approximately every 15 days. The spring tide period was determined as the time of each yellow point \pm 1 day. The neap tide period was set to \pm 1 day from a point at -7.5 days relative to the peak of the spring tide. The spring tide (red lines) and neap tide (green lines) can be distinguished clearly, and they exhibit the semidiurnal tidal characteristic $[1,2]$. During this period, the sea level range during the spring tide, as shown in Figure 3a, was approximately $200 \mathrm{~cm}$, whereas the range of the neap tide was approximately $60 \mathrm{~cm}$, which differed sharply from that of the spring tide. Due to this difference, the tidal current velocity will change between the spring tide and neap tide. The overall level of underwater noise, shown in Figure 3b, exhibits a similar tendency to that of sea level. The noise level was high during the spring tide period (red lines), low during the neap tide period (green lines), and appeared to be closely correlated with sea level. The red dotted line in Figure $3 \mathrm{~b}$ indicates the mean value $(110.0 \mathrm{~dB})$ of the overall noise levels during the spring tide period. The green dotted line indicates the mean value $(97.9 \mathrm{~dB})$ during the neap tide period. These two mean values have a large difference of $12.1 \mathrm{~dB}$, which may be due to the change in tidal current velocity.
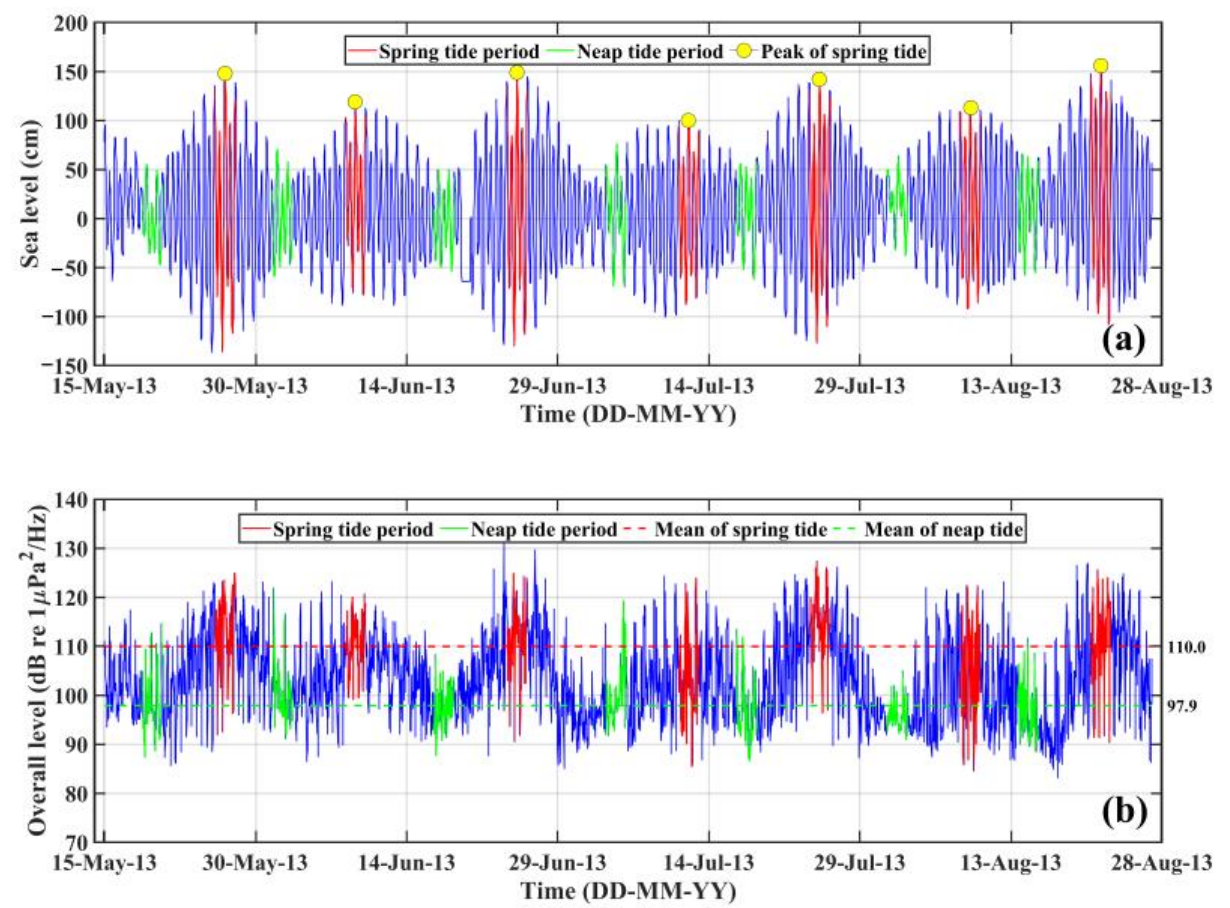

Figure 3. (a) Sea level and (b) overall level of underwater noise from 15 May to 27 August 2013. The red and green lines indicate spring tide and neap tide periods, respectively. Yellow points indicate the peaks of the spring tide. The number at the end of the red dotted line is the average for the spring tide, and the number at the end of the green dotted line is the average for the neap tide. 
Figure 4 shows frequency spectra of underwater noise during the spring and neap tide periods. The thick solid lines in Figure 4 represent the average frequency spectra of underwater noise during the spring tide (red) and neap tide (green). The frequency spectra for the spring tide period exhibited large differences; in particular, at low frequency (below $50 \mathrm{~Hz}$ ), noise levels varied from 67.2 to $119.1 \mathrm{~dB}$, with an average range of 99.0-106.6 dB. Smaller differences were observed for the neap tide, with a low-frequency (below $50 \mathrm{~Hz}$ ) range of 65.4-108.3 dB. The average range was 78.4-90.2 dB. The difference between the two average frequency spectra during both tide periods was approximately 12.6-20.7 $\mathrm{dB}$ below $50 \mathrm{~Hz}$. The difference was less than $8.3 \mathrm{~dB}$ at frequencies of more than $60 \mathrm{~Hz}$.

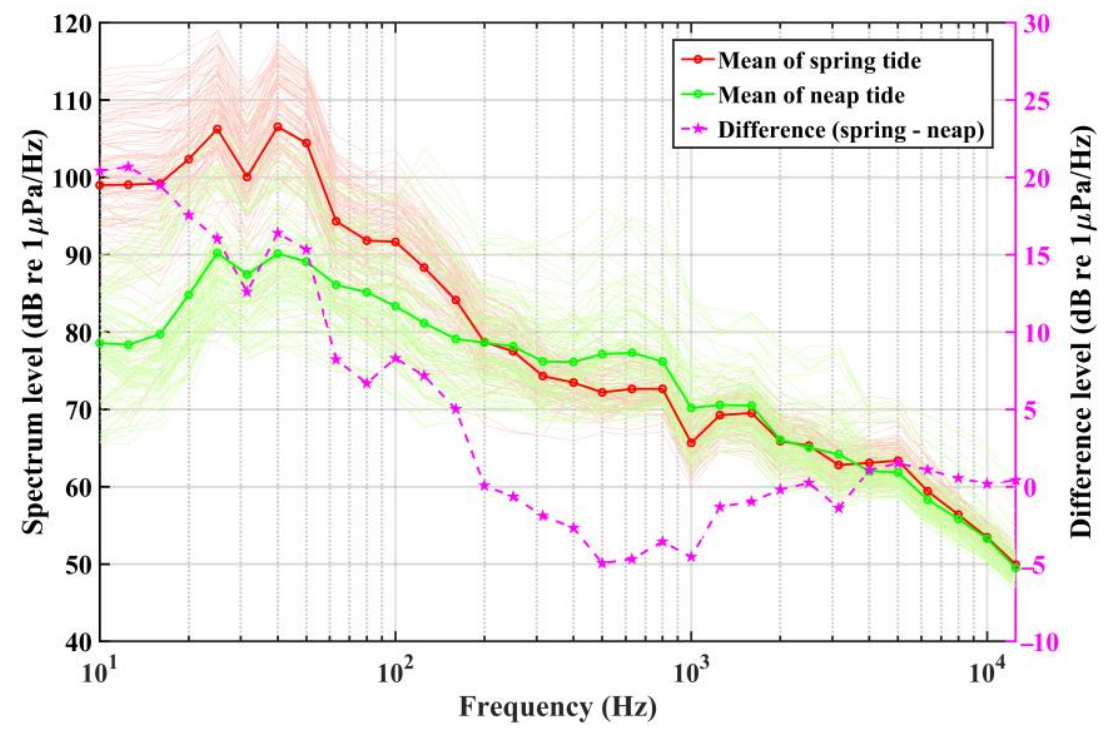

Figure 4. Frequency spectra of underwater noise during spring and neap tide periods. The thick solid lines represent the average frequency spectra of underwater noise during the spring tide (red) and neap tide (green). The magenta line indicates the differences between the two average frequency spectra.

Figure 5 shows the overall levels of underwater noise from 15 May to 27 August 2013. The $x$-axis in Figure $3 \mathrm{~b}$ represents the total time of the measurement period, and the $y$-axis represents the time of day. The overall noise level was within the range of 90-125 dB, with a pattern of low and high levels every 6-8 days. When the overall level was high, it was more than $115 \mathrm{~dB}$, and when it was low, it was less than $90 \mathrm{~dB}$. These patterns of high and low noise occurred within a cycle of approximately 15 days. However, noise levels over $24 \mathrm{~h}$, as indicated by the y-axis of Figure 5, were not consistently high or low due to variations in tidal current velocity, which affected the underwater noise level. The point of high or low water during the tidal cycle, when there is little or no change in the height of the tide, is known as the stand of the tide. The sea level is almost stationary at the stand of the tide, and the tidal current velocity falls to zero before reversing. Therefore, the overall level of underwater noise was lowest at the stand of the tide, which occurs four times per day. 


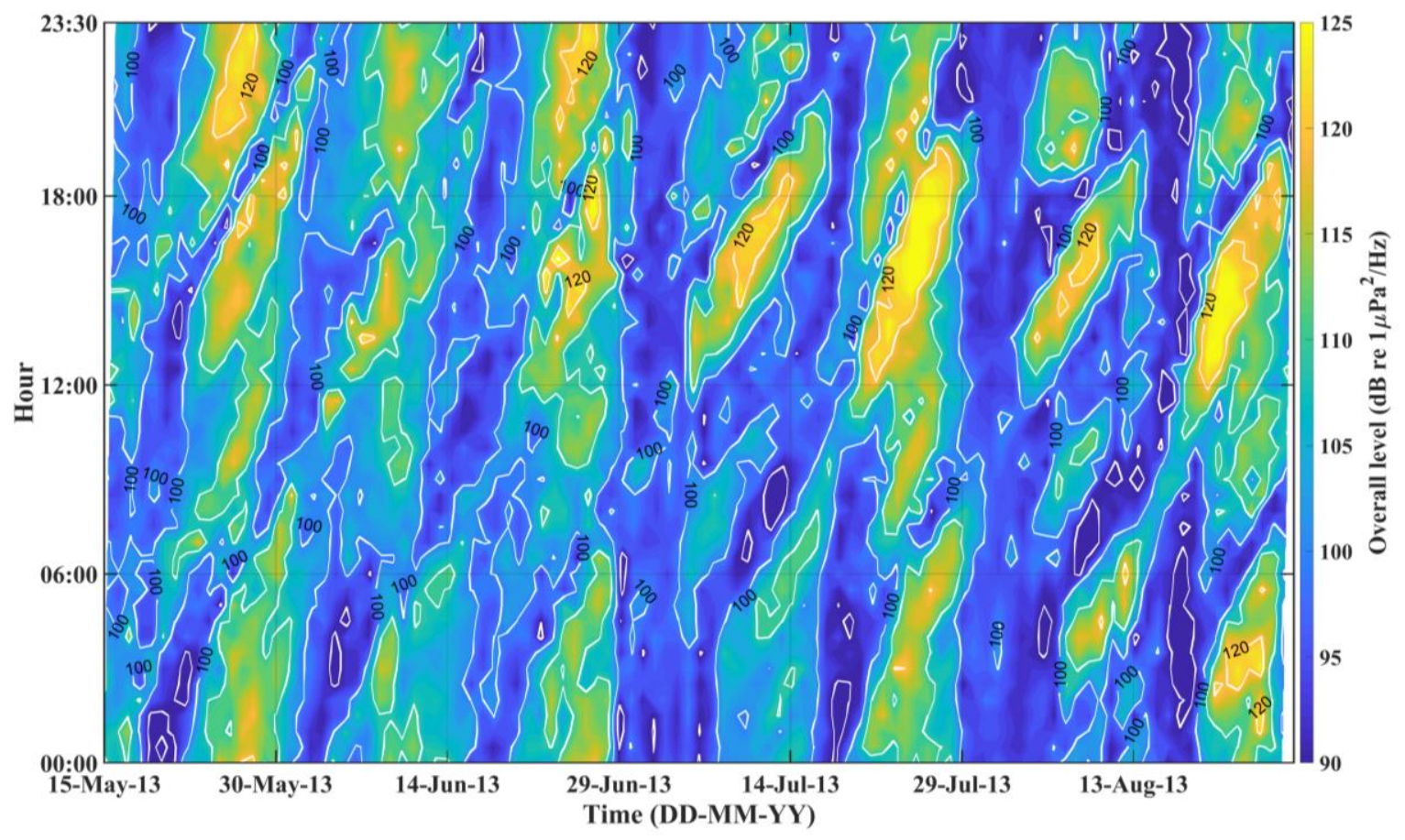

Figure 5. Overall levels of underwater noise (contour label interval, 10 dB) from 15 May to 27 August 2013.

\section{Discussion}

\subsection{The Correlation between Underwater Noise and Sea Level}

Figure 6 shows the correlation between the absolute value of sea level and the overall level of underwater noise with and without low-pass filtering at six hours. As shown in Figure 6, the correlation coefficient between sea level and overall level of underwater noise had a low value of 0.33 . However, the coefficient had a high value of 0.70 when a low-pass filter at six hours was applied to the noise level data, as low-pass filtering removed short periodic components caused by nearby shipping vessels or sea surface agitation [4,5,8-12].
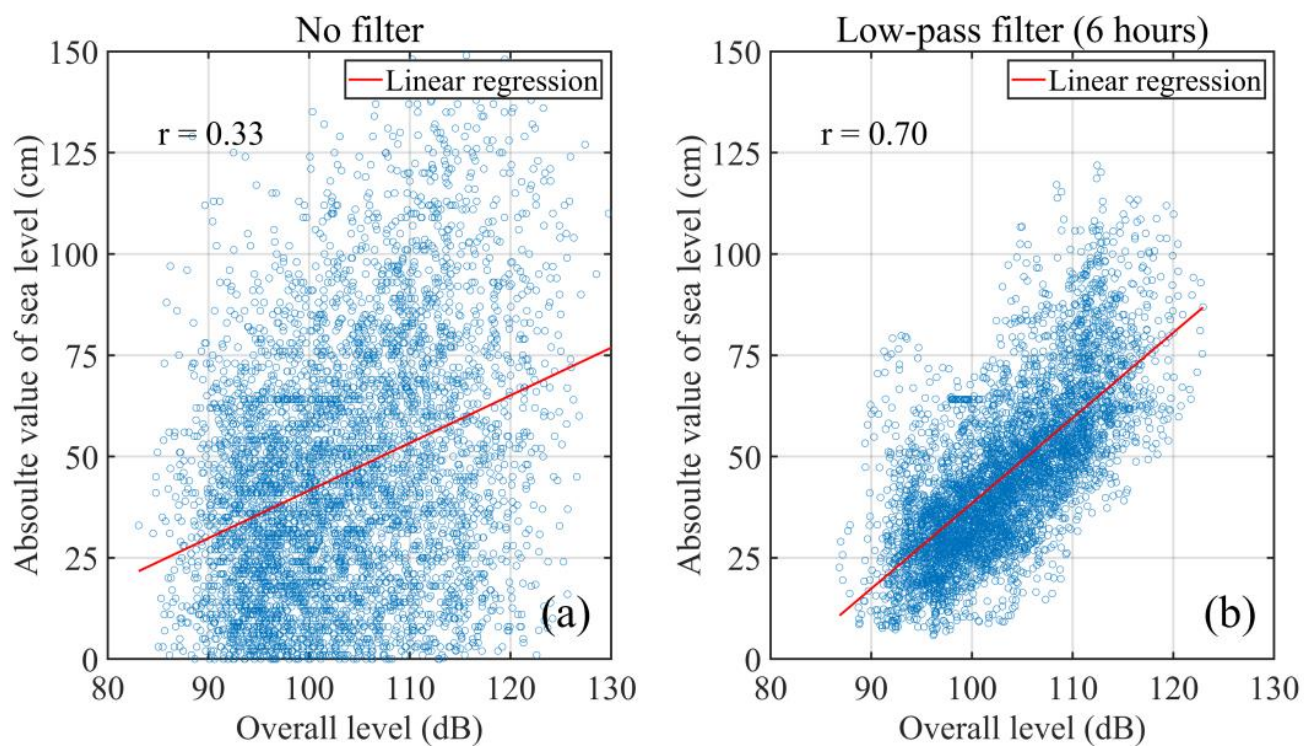

Figure 6. Correlation between the absolute value of sea level and overall underwater noise level (a) without and (b) with low-pass filtering at $6 \mathrm{~h}$. 
Figure 7 shows the correlation coefficients between sea level and underwater noise level at different $1 / 3$-octave frequencies. The red dotted line indicates a correlation coefficient of 0.70 for the overall level of underwater noise. The correlation coefficient for underwater noise was generally high at frequencies below approximately $50 \mathrm{~Hz}$ and had a maximum value of 0.71 around the frequency of $16 \mathrm{~Hz}$, which was similar to the overall level. Underwater noise at frequencies below $50 \mathrm{~Hz}$ can be caused by tidal currents and, therefore, is related to sea level $[16,18]$.

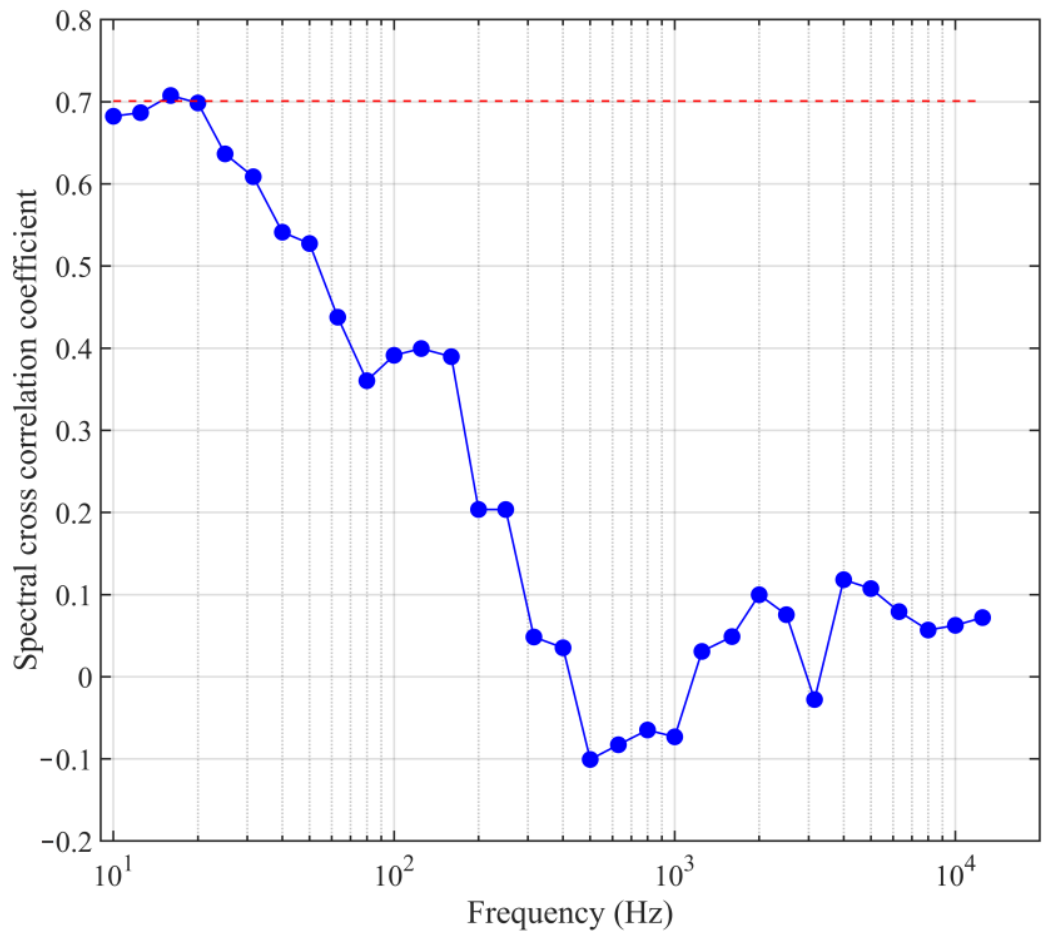

Figure 7. Spectral cross correlation coefficients between sea level and underwater noise level at various $1 / 3$-octave frequencies.

\subsection{Continuous Wavelet Analysis of Sea Level and Overall Underwater Noise Level}

Figure 8 shows the results of continuous wavelet analysis of sea level and overall underwater noise level. As shown in Figure 8a, wavelet analysis of sea level revealed strong periodicity at $0.25(6 \mathrm{~h}), 0.5(12 \mathrm{~h}), 1(24 \mathrm{~h}), 13.6$, and 27.6 days. Wavelet analysis of underwater noise revealed a similar pattern of periodicity, as tidal currents significantly affected the underwater noise level. For the semidiurnal tides, which are the main tidal constituent, the period of the principal lunar component $\left(\mathrm{M}_{2}\right)$ was $12.42 \mathrm{~h}$ and the period of principal solar component $\left(\mathrm{S}_{2}\right)$ was $12.00 \mathrm{~h}$. Among diurnal factors, the lunisolar period $\left(\mathrm{K}_{1}\right)$ was $23.93 \mathrm{~h}$ and the principal lunar period $\left(\mathrm{O}_{1}\right)$ was $25.82 \mathrm{~h}$. Among tidal constituents acting over longer periods, the period of the lunar fortnightly constituent $\left(\mathrm{M}_{\mathrm{f}}\right)$ was $327.9 \mathrm{~h}$ (13.66 days) and the period of the lunar monthly constituent $\left(\mathrm{M}_{\mathrm{m}}\right)$ was $661.30 \mathrm{~h}$ (27.55 days; Table 1) [22]. In the underwater noise data, these tidal constituents could be readily identified and their periods were consistent. These results validate the possibility of measuring tidal constituents based on underwater noise. 


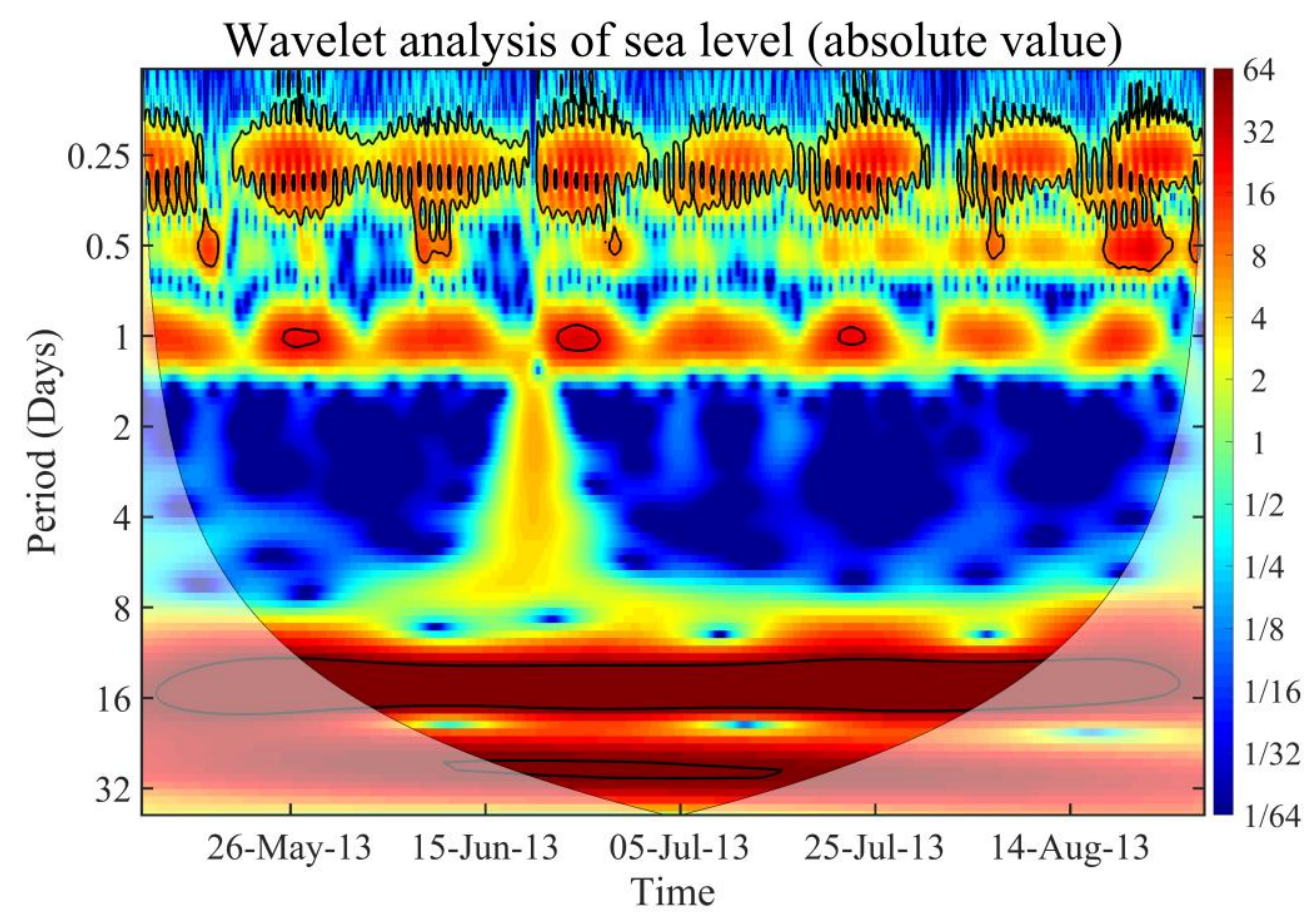

(a)

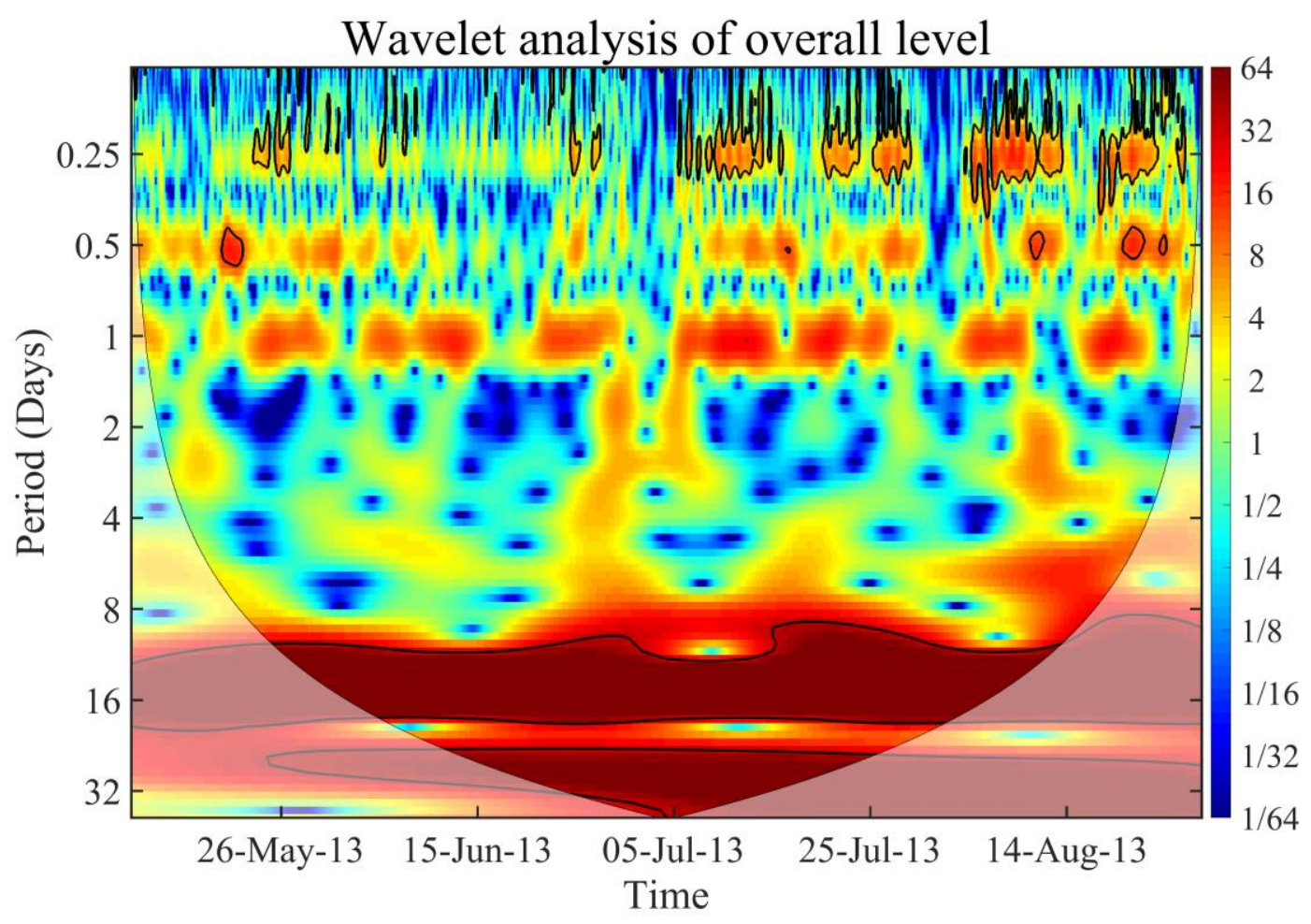

(b)

Figure 8. The continuous wavelet power spectrum of (a) sea level and (b) the overall level of underwater noise. The tick black contour designates the $5 \%$ significance level against red noise and the cone of influence (COI) where edge effects might distort the picture is shown as a lighter shade. 
Table 1. Characteristics of principal tidal constituents.

\begin{tabular}{cccc}
\hline Type and Name & Symbol & $\begin{array}{c}\text { Period } \\
\text { (Solar Hours [Days]) }\end{array}$ & $\begin{array}{c}\text { Relative Size } \\
\text { (\%) }\end{array}$ \\
\hline Semi-diurnal & & & \\
Principal lunar & $\mathrm{M}_{2}$ & $12.42(0.52)$ & 100.0 \\
Principal solar & $\mathrm{S}_{2}$ & $12.00(0.50)$ & 46.6 \\
$\quad$ Diurnal & & & 58.4 \\
Lunisolar & $\mathrm{K}_{1}$ & $23.93(1.00)$ & 41.5 \\
Principal lunar & $\mathrm{O}_{1}$ & $25.82(1.08)$ & 17.2 \\
Long period & & & 9.1 \\
Lunar fortnightly & $\mathrm{M}_{\mathrm{f}}$ & $327.67(13.65)$ & \\
Lunar monthly & $\mathrm{M}_{\mathrm{m}}$ & $661.30(27.55)$ & \\
\hline
\end{tabular}

\subsection{Dependence of Sea Level and Overall Underwater Noise Level on Current Velocity}

Figure 9 shows the wavelet coherence between sea level and overall underwater noise level. As shown in Figure 9, coherence was very high at periods of 0.25, 0.5, and 1 day. This finding indicates that underwater noise strongly influenced sea level variations. Coherence was also very high at periods of 8-32 days. The arrows in Figure 9 indicate the phase between sea level and noise level [21]. The relative phase relationships are indicated with arrows (with those pointing right, left, and straight down indicating an in-phase relationship, an anti-phase relationship, and that sea level was leading underwater noise by $90^{\circ}$, respectively). The arrows situated at a period of 0.25 day (six hours) in Figure 9 indicate phase differences of approximately $-90^{\circ}$, which means that the noise level peak occurred at $1.5 \mathrm{~h}$ earlier than the sea level peak. The time lag between the noise peak and the sea level peak indicates that the tidal current velocity did not reach its maximum during the peak of sea level. Current velocity is generally slowest at low tide and high tide but may vary depending on the geographic characteristics of shallow waters.

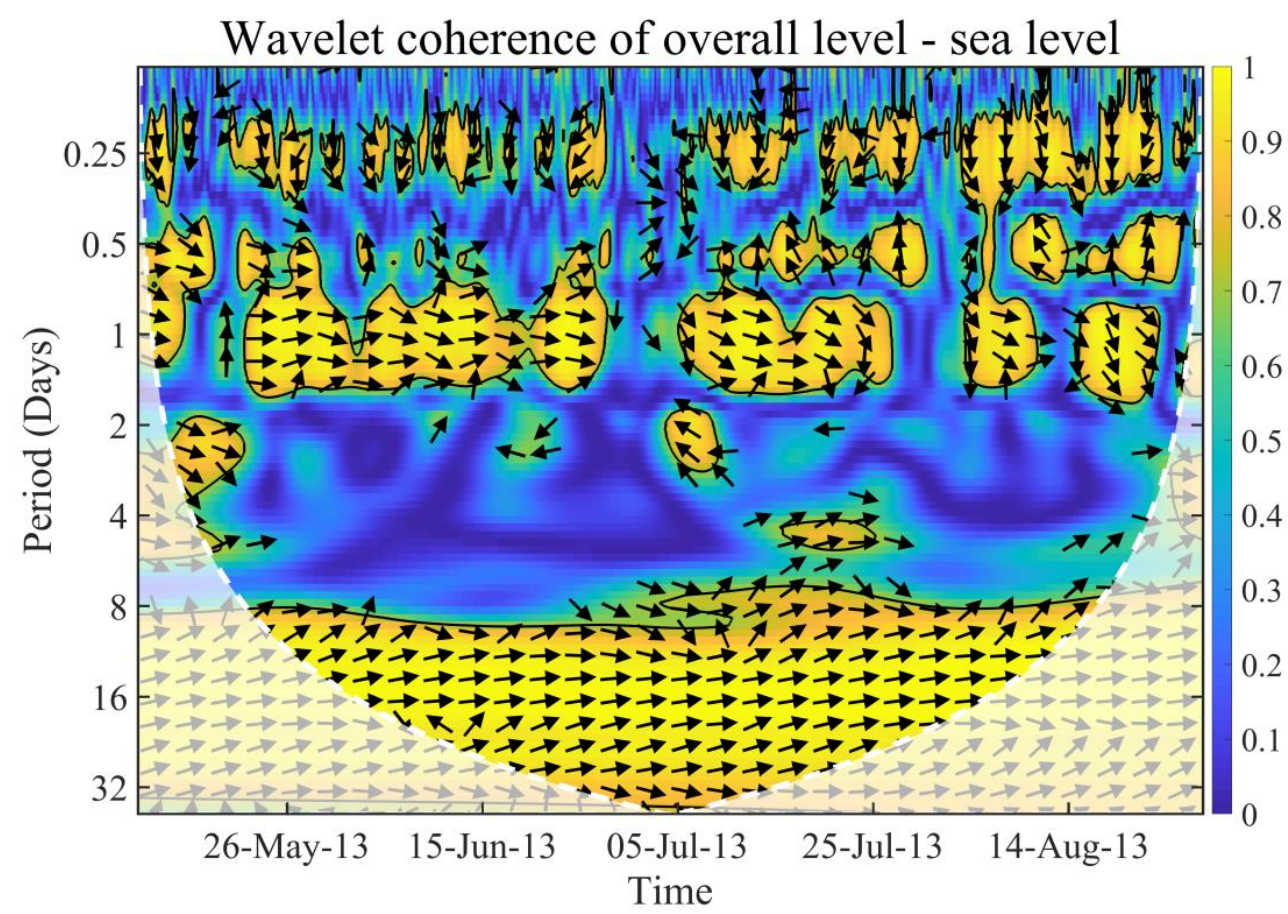

Figure 9. Wavelet coherence analysis of underwater noise (overall level) and sea level. The relative phase relationship is indicated with arrows as follows: pointing right, in-phase; pointing left, anti-phase; pointing straight down, sea level leading underwater noise by $90^{\circ}$. The $5 \%$ significance level again red noise is shown as a thick contour. The cone of influence (COI) where edge effects might distort the picture is shown as a lighter shade. 
Figure 10 shows the correlation coefficients between the overall level of underwater noise without low-pass filtering and sea level calculated using various time lags at $0.5-\mathrm{h}$ intervals. The correlation coefficient was 0.33 with a time lag of $0 \mathrm{~h}$, then increased to 0.44 with a lag of $0.50 \mathrm{~h}$ and had its highest value of 0.57 with a lag of $1.5 \mathrm{~h}$. The coefficient decreased from 0.56 to 0.07 with $2.0-5.0 \mathrm{~h}$ time lags, and then increased again from 0.12 to 0.49 with $5.5-8.0 \mathrm{~h}$ time lags. Consequently, the maximum velocity of the tidal current occurred at approximately $1.5 \mathrm{~h}$ from the high tide and low tide in terms of sea level.

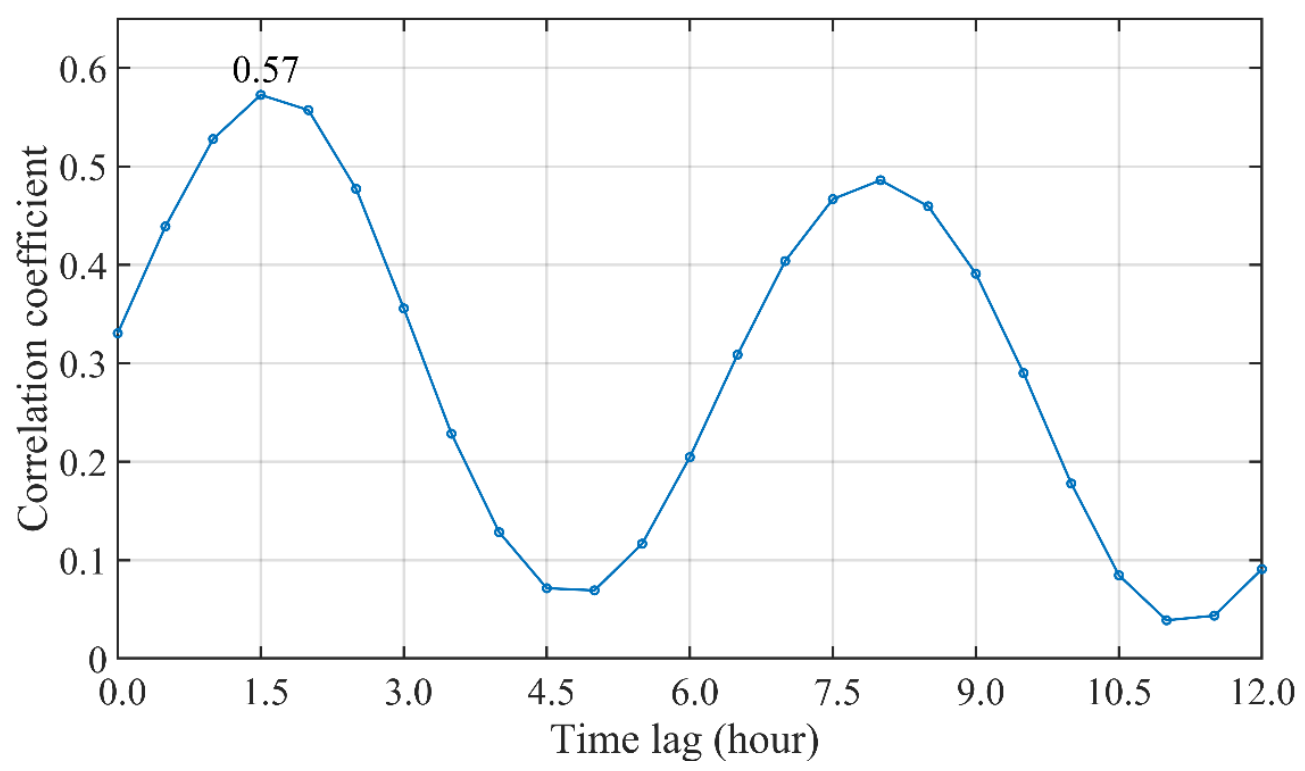

Figure 10. Correlation coefficients between the overall level of underwater noise (no low-pass filtering) and sea level calculated with various time lags at $0.5-\mathrm{h}$ intervals.

Figure 11 shows the sea level and noise level averaged at each time point over $24 \mathrm{~h}$ based on the timing of the high tide on each day. As shown in Figure 11, the sea level (red line) falls from high tide to low tide over a period of approximately $6.5 \mathrm{~h}$. Underwater noise exhibits a periodicity similar to that of sea level. However, the noise level is high at $1.5 \mathrm{~h}$ before the times of the low and high tides. Thus, the peak level of underwater noise occurred at $1.5 \mathrm{~h}$ earlier than the peak of sea height. This result is similar to that reported by Willis et al. [18]. As underwater noise at frequencies below $100 \mathrm{~Hz}$ is related to tidal currents $[16,18]$, the maximum level of underwater noise observed at $1.5 \mathrm{~h}$ before the low and high tides, as shown in Figure 11, may be significantly driven by ebb and flood currents. Noise levels during the ebb and flood currents were 109.1 and $105.8 \mathrm{~dB}$, respectively. This difference in noise level between currents might have been caused by a difference in current velocity.

Figure 12 shows the current velocity and sea level measured from 17 October 2009 to 20 February 2010. The current velocity was not measured during the experimental period because the RDCP was lost due to a fishing vessel, as noted in Section 2.2. Generally, monthly volatility of the current velocity is not expected to be high, but daily changes can be expected. In the daily pattern of current velocity, the ebb current was fastest at $1.5-2.0 \mathrm{~h}$ before the low tide, reaching velocities of 86.8 and $87.6 \mathrm{~cm} / \mathrm{s}$. The maximum flood current velocities were 82.3 and $80.2 \mathrm{~cm} / \mathrm{s}$ before the high tide, which were somewhat lower than the ebb current velocities. Therefore, the periodicity of underwater noise in this study appears to be strongly related to tidal currents. 


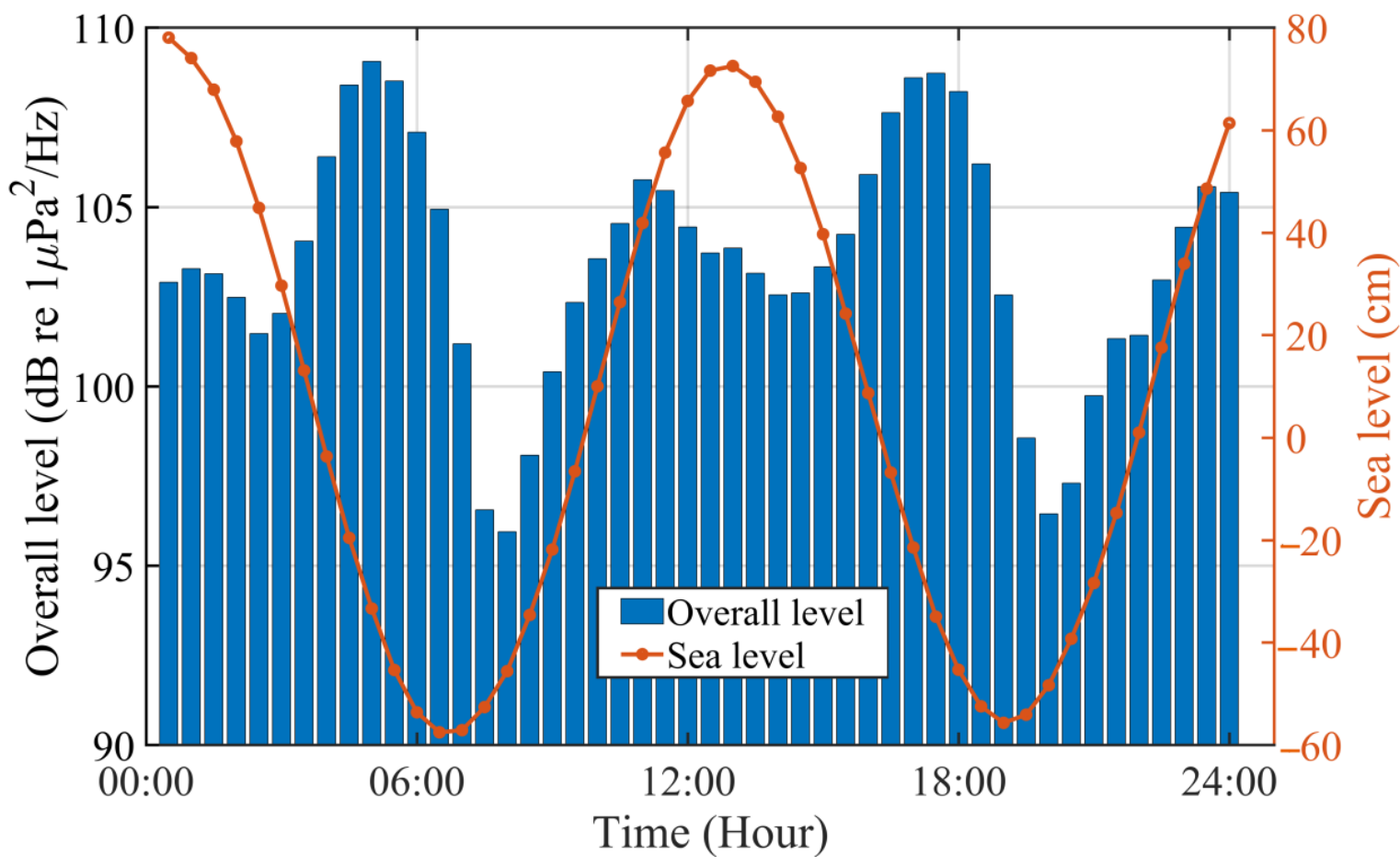

Figure 11. Sea level (red line) and overall level of underwater noise (bars) averaged at each time point over $24 \mathrm{~h}$ based on the timing of high tides each day from 15 May to 27 August 2013.

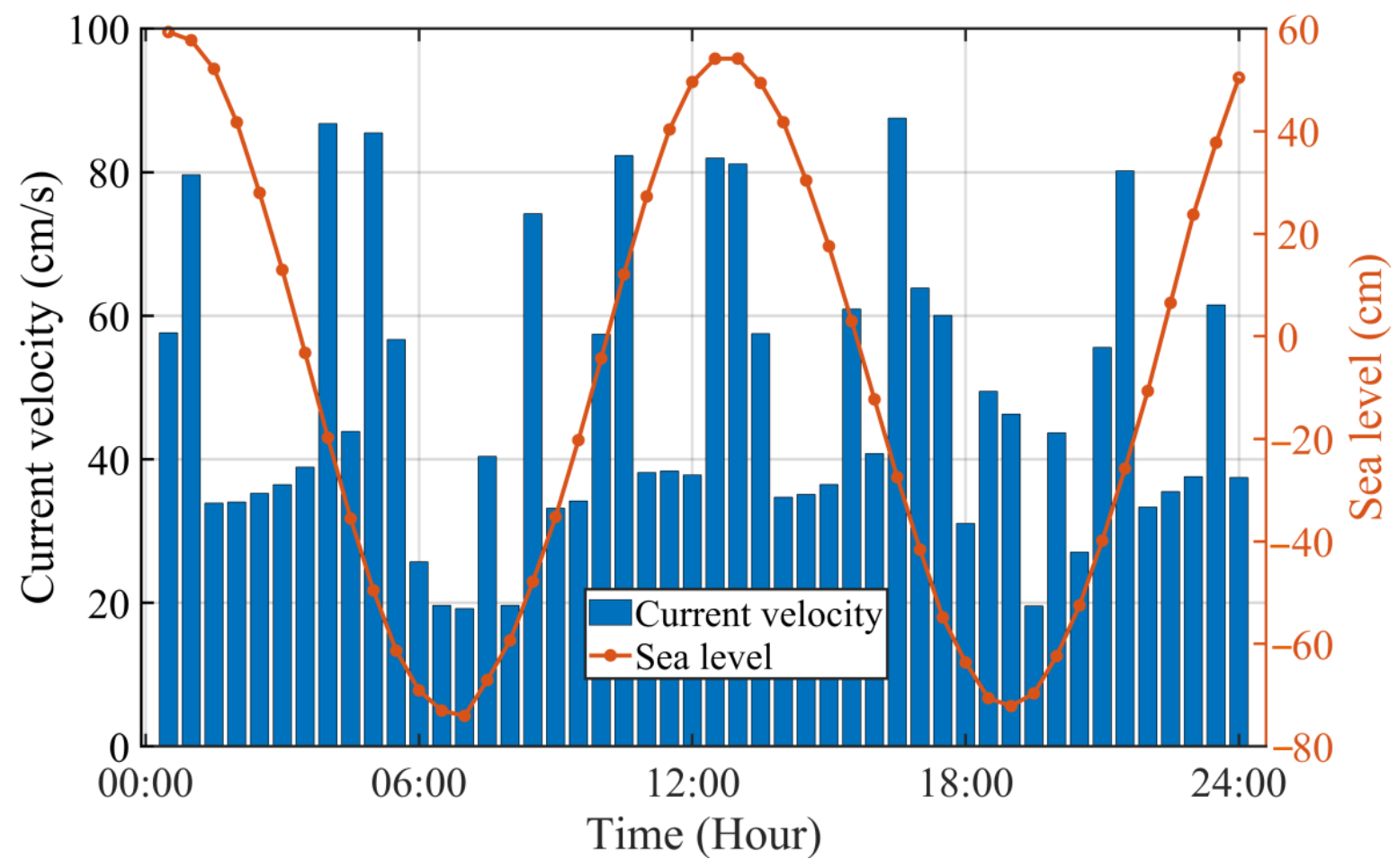

Figure 12. Current velocity (bars) and sea level (red line) from 17 October 2019 to 20 February 2010. 


\section{Conclusions}

The correlation between underwater noise and sea level as measured at IORS was analyzed. Underwater noise was converted to overall levels. The overall level of underwater noise during the spring tide was $99.0-106.6 \mathrm{~dB}$. It was 78.4-90.2 dB at neap tide, with a large difference of $20.6 \mathrm{~dB}$ observed between tidal periods. The average underwater noise levels at frequencies below $50 \mathrm{~Hz}$ were 99.0-106.6 dB during spring tides and 78.4-90.2 dB during neap tides, with a difference of 12.6-20.6 dB. The correlation coefficient between the overall level of underwater noise and sea level was high (0.7), which may be related to flow noise at low frequencies caused by tidal currents. Thus, underwater noise around the frequency of $16 \mathrm{~Hz}$ exhibited a strong correlation (0.71) with sea level. On the other hand, the correlation coefficients at frequencies above $60 \mathrm{~Hz}$ were less than 0.5 and the correlation was low.

Wavelet analysis of underwater noise and sea level revealed strong periodicity at 0.25 (6 h), $0.5,1,13.6$, and 27.6 days, similar to the tidal constituents. Wavelet coherence analysis revealed very high coherence at $0.25,0.5$, and 1 day. In particular, the arrows representing the 0.25 day period indicated a phase difference of approximately $-90^{\circ}$, indicating that the overall level of underwater noise peaks at $1.5 \mathrm{~h}$ earlier than sea level. Correlations were calculated with time lags between the noise level and sea level at $0.5 \mathrm{~h}$ intervals, and the highest correlation coefficient of 0.57 was obtained with a time lag of $1.5 \mathrm{~h}$. The overall level of underwater noise was high at $1.5 \mathrm{~h}$ before the low and high tides. Therefore, the peak noise level occurred at $1.5 \mathrm{~h}$ earlier than the peak sea level. The maximum noise levels during ebb and flood currents were 109.1 and $105.8 \mathrm{~dB}$, respectively. The difference between ebb and flood currents might have been caused by a difference in current velocity. In the daily current velocity measurements, the fastest ebb current was $86.8 \mathrm{~cm} / \mathrm{s}$, which occurred at $1.5-2.0 \mathrm{~h}$ before the low tide. We confirmed that the current velocity is strongest before the low tide and high tide. This finding indicates that underwater noise at IORS may be significantly related to tidal currents. Future research on the correlation between underwater noise and tidal currents (current velocity) should focus on the prediction of tidal currents using underwater noise levels.

Author Contributions: Conceptualization, B.K.C. and B.-N.K.; methodology, S.H.K.; software, S.H.K.; formal analysis, B.-N.K.; investigation, B.-N.K. and S.H.K.; data curation, B.K.C.; writing-original draft preparation, S.H.K.; writing—review and editing, B.-N.K. and B.K.C.; visualization, S.H.K.; supervision, B.K.C.; project administration, B.K.C.; funding acquisition, B.K.C. All authors have read and agreed to the published version of the manuscript.

Funding: This research was part of the project titled "Construction of ocean research stations and their application studies (grant no. PM61730)" and "Development of Ocean Acoustic Echo Sounders and Hydro-Physical Properties Monitoring Systems (grant no. PM61980)" funded by the Ministry of Oceans and Fisheries, Korea. This work was also a part of the project titled "Development of technology on survivor search and survivability assurance in the accident ship", funded by the Korea Coast Guard, Korea (grant no. PM61990).

Data Availability Statement: The data presented in this study are available on request from the corresponding author.

Acknowledgments: Thanks are due to Eung Kim, Ho Yoon Ji, for their valuable guidance and discussion.

Conflicts of Interest: The authors declare no conflict of interest.

\section{References}

1. Kim, S.H.; Choi, B.K.; Kim, E. Study on the Behavior of the Water Temperature Inversion Layer in the Northern East China Sea. J. Mar. Sci. Eng. 2020, 8, 157. [CrossRef]

2. OH, K.H.; Park, Y.G.; Lim, D.I.; Jung, H.S.; Shim, J.S. Characteristics of temperature and salinity observed at the Ieodo ocean research station. J. Korean Soc. Mar. Environ. Energy 2006, 9, 225-234, (Abstract only Korean).

3. KHOA (Korea Hydrographic and Oceanographic Agency). About Ocean Research Station. Available online: http:/ /www.khoa. go.kr/eng/kcom/cnt/selectContentsPage.do?cntId=31080200 (accessed on 1 July 2020). 
4. Knudsen, V.O.; Alford, R.S.; Emling, J.W. Underwater ambient noise. J. Mar. Res. 1948, 7, 410-429.

5. Wenz, G.M. Acoustic ambient noise in the ocean: Spectra and sources. J. Acoust. Soc. Am. 1962, 34, 1936-1956. [CrossRef]

6. Strasberg, M. Nonacoustic noise interference in measurements of infrasonic ambient noise. J. Acoust. Soc. Am. 1970, 66, 1487-1493. [CrossRef]

7. Buck, B.M.; Greene, C.R. A two-hydrophone method of eliminating the effects of nonacoustic noise interference in measurements of infrasonic ambient noise levels. J. Acoust. Soc. Am. 1980, 68, 1306-1308. [CrossRef]

8. Lemon, D.D.; Farmer, D.M.; Watts, D.R. Acoustic measurements of wind speed and precipitation over a continental shelf. J. Geophys. Res. 1984, 89, 3462-3472. [CrossRef]

9. Nystuen, J.A. Rainfall measurements using underwater ambient noise. J. Acoust. Soc. Am. 1986, 79, 972-982. [CrossRef]

10. Urick, R.J. Principles of Underwater Sound, 3rd ed.; Peninsula Publishing: Los Altos CA, USA, 1983; pp. $202-233$.

11. Urick, R.J. Ambient Noise in the Sea; Peninsula Publishing Los Altos: CA, USA, 1986; pp. 1-42.

12. Kim, B.C.; Choi, B.K.; Byun, S.K. The Wind Speed Dependence of Oceanic Ambient Noise Level in the Shallow Water of Sokcho Coast. Ocean Res. 1996, 18, 93-99, (Abstract only Korean).

13. Deane, G.B. Long time-base observations of surf noise. J. Acoust. Soc. Am. 2000, 107, 758-770. [CrossRef] [PubMed]

14. Choi, B.K.; Kim, B.C.; Kim, B.N. Analysis of dependence on wind speed and ship traffic of underwater ambient noise at shallow sea surrounding the Korean peninsula. J. Acoust. Soc. Kr 2003, 22, 233-241, (Abstract only Korean).

15. Haxel, J.H.; Dziak, R.P.; Matsumoto, H. Observations of shallow water marine ambient sound: The low frequency underwater soundscape of the central Oregon coast. J. Acoust. Soc. Am. 2013, 133, 2586-2596. [CrossRef] [PubMed]

16. Bassett, C.; Thomson, J.; Dahl, P.H.; Polagye, B. Flow-noise and turbulence in two tidal channels. J. Acoust. Soc. Am. 2014, 135, 1764-1774. [CrossRef] [PubMed]

17. Revie, J.; Weston, D.E. Hydrophone signal due to tidal and wave effects. J. R. Nav. Sci. Serv. 1970, 25, 185-187. [CrossRef]

18. Willis, M.R.; Broudic, M.; Haywood, C.; Masters, I.; Thomas, S. Measuring underwater background noise in high tidal flow environments. Renew. Energy 2013, 49, 255-258. [CrossRef]

19. Kinsler, L.E.; Frey, A.R.; Coppens, A.B.; Sanders, J.V. Fundamentals of Acoustics, 4th ed.; Wiley-VCH: New York, NY, USA, 1999; pp. 306-307.

20. Available online: http://www.khoa.go.kr/oceangrid/khoa/koofs.do (accessed on 31 August 2020).

21. Grinsted, A.; Moore, J.C.; Jevrejeva, S. Application of the cross wavelet transform and wavelet coherence to geophysical time series. Nonlinear Process. Geophys. 2004, 11, 561-566. [CrossRef]

22. Knauss, J.A.; Garfield, N. Introduction to Physical Oceanography, 3rd ed.; Waveland Press, Inc.: Long Grove, IL, USA, 2017 ; p. 245. 